Artan

Sadiku

\title{
Provocation to a Final Resistance of Truth: Ethics of a Heretical Discourse
}

It often happens that we are compelled to look at the World through the spectre of established discourses of thought and announcements that attempt to think, explain and speak of the World in a Foucauldian manner of systematization. The postmodern explosion of discourses that has produced an unprecedented vastness of numerous philosophical theory has inescapably been pinned to the regularities of Focauldian discursive formation. In criticizing the essence of this pinning process of philosophical theory Katerina Kolozova in The Real and "I:" On the Limit and the Self deploys a radical criticism of the inherent auto-legitimization and auto-constitution present in the founding conceptual constructs of the discourse, providing a way-out through Laruellian nonphilosophy (Kolozova 2006). Non-philosophy's thought in terms with the Real, which would escape the present doctrinal discursive regularities, is what she proposes for an entirely different discursivity. It is precisely that kind of discursivity, one that operates in Laruellian terms of the Real that I will put in line with Badiou's ethics in order to move towards a possible ethical discourse.

Namely, Badiou's ethics is one of truths, one that reveals itself in the fidelity to the events that supplement a situation by thinking that situation according to those events. Events come upon the subject as unpredictable and mean nothing according to the prevailing discourses, thus truth is nowhere to be found in the discourse un-supplemented by events. Foucauldian discursive construction of truths through relational analyses that remain within the predictable world of established knowledge and prevailing language is thusan unethical discursive procedure (in relation to truths). With thought and language as discourse's main operatives, an ethical discourse must therefore inherently involve ethics of truth in their respective operations.

To do this, Badiou requires a constitution of a subject of truth, the one that will link the discursive things he knows via the effects of being seized by the unknown (the experience of the encounter, Badiou 2001, 40-57). It is the decision of fidelity to what has seized a subject that produces him through the event as a subject of truth in relation to his situation (or his World). Thus events are only possibilities for truth procedures dependant on the decision of the subject to enact his fidelity in relation to the situation. Thus the truth is reducible to a subjective decision of fidelity! Badiou himself points to the 
uncertainty of fidelity, which is a matter of interest as the sole principle of perseverance (of the human animal or the "some-one") as perseverance in being as opposed to a disinterested-interest that would count for a pure interest which would preserve "some-one" into eventual fidelity. It is exactly due to this uncertainty, he says, that there is a place for the ethics of truth (ibid., 69). Making this assertion, Badiou does nothing unexpected, he actually entirely employs the known philosophy of differentiation, differentiation of the ethics of truth through its other that is the one of the non-fidelity. At this point Badiou's ethics do not help to fully move towards sketching out, as Kolozova says, a radically different (ethical) discourse. It does not help simply because its founding operational method is one of (philosophical) decisions which throw us back to the ones employed by the classical discourses. To be clear, Badiou sets in motion a whole new set of radical (in philosophical terms) ethics of truth in relation to the prevailing discourses, but the very problem of these ethics is its radicality beyond philosophy. In continuing to relate to his ethics, I will depart from his philosophy taking along only his radical concept of truth (coming from the unknown/unpredictable) in a quest for a radical ethics out of philosophy, into non-philosophy.

In a fashion similar to Badiou's one of the truth procedure, Laruelle seeks the production of truths as a result of an encounter (event) with the Real that puts forward a posture of thought. That is a way of theorizing in correlation with the Real, a correlation that does not attempt to grasp it, but it only correlates with it by way of acknowledging it to be the decisive instance of legitimization of the produced truth. (Kolozova 2006, 69) It might seem at this moment that the posture of thought (or thinking in terms of the Real) is the way forward insketchingan ethical discourse, one that appropriates Kolozova's reading of Laruelle:

...Hence, the Thought in terms of the Real is "absolute" in a very distinct sense: it is solitary in its singularity, an effort of Thought exposed in its ultimate incapacity to grasp and control the Rule-of-the-Real, yet attempting to correlate but with it, without the support of a doctrinal web made of philosophical decisions. (ibid., 41)

It is exactly this indifference to the philosophical decisions that is radically different in non-philosophy's account of a different doctrine.

Since the sole element of truth production-procedure is the fidelity to the truth that has emerged through the experience with the Real (the lived), then we must explore the performance of this fidelity (already explored above in Badiou's philosophy) within the field of non-philosophy. Precisely here, non-philosophy offers a radically different account for fidelity, one that is indifferent to decisions (present in Badiou) and that is more faithful to the true nature of the encounter/event. Badiou says on the effects of the event that "being altogether there (in the eventual site) one is also suspended, broken, annulled and disinterested." Finding himself in the midst of an event, the some-one that has experienced an undergoing passing through him that has supplemented his being (the excess beyond himself) is faced with the imperative of dealing/linking with the things he knows, the present in the situation (language/discourse). While Badiou draws a lot of his philosophy of the event/encounter (with the Real) from Lacanian psychoanalysis, he misses the 
crucial moment (which in Badiou is a choice to move within a situation supplemented by the event) of fidelity formation. Whereas Lacan ascribes a deterministic nature to the event (or Tuché which he borrows from Aristotle and translates it as the encounter with the real (Lacan 1998, 53)) over what Badiou calls fidelity (where I believe Kolozova does more justice to the nature of its formation by naming it "a call to action" by Trauma): "Is it not remarkable that, at the origin of the analytic experience, the Real should have presented itself in the form of that which is unassimilable in it - in the form of the trauma, determining all that follows, and imposing on it an apparently accidental origin?" (ibid., 54-55) It is exactly the traumatic nature of the encounter/event that determines all that follows rendering a decision to fidelity impossible. Thus there cannot be any talk of uncertainty (over the possible course of the interest, that of preserving in being or preserving in the disinterested) which in Badiou is the reason why there is a place for ethic of truths. What remains form Badiou's philosophy of the event are the radical truths steaming out of truth procedures, but what fails the test in much of Badiou's own terms is the ethics which is reduced in the classical philosophical decision of differentiation through the other. This move fundamentalizes the decision as such, as the core principal move of ethics which then can easily be applied to the discursive production of truths, running from one decision to another, which is in contradiction with Badiou's truth procedures.

A radical question appears when exploring the fidelity/ call to action of the subject who has experienced the trauma as the effect of the Real, One that is related to the post-traumatic actions of the subject. This question can be summarized as follows: How does the subject (of truth), which Kolozova sees as the one that is borne out of the very necessity to incessantly strive to avoid the traumatic experience - the immediacy of the Real (Kolozova $2009,9)$, continue to think in terms with the Real (the immediacy of which is Trauma) which he strives to avoid? Striving to avoid the real does not lead to successful avoidance of the Real, it is rather exactly this possibility that brings forward the subject himself (who as such can then think in terms of the Real). Kolozova brings up Žižek's epistemic possibility that is one of antagonism, further claiming that "Antagonism as Real or, rather, the Real as antagonism is what conditions the Subject, what grounds its very possibility." (Ibid..) If this antagonism that produces the subject who is born in the escape from the experienced is The Real, then thinking in terms of The Real would imply thinking in terms of some antagonism, which implies some kind of opposition. Self-opposition in thinking by the subject fulfils the non-philosophical proposal for thinking in terms of the Real as thinking by way of abandoning Thought's auto-referential obsession (by way of self-situating with respect to the Real) performs the theoretical gesture of its own self-suspension. (Kolozova 2006, 74) Thus this gesture of self-suspension of thought (in Terms with the Real) can be said to be inherent in the Real itself (as antagonism).

I believe that it is possible to explore another possibility in the form of a motivation to think in terms with the Real which rests on the search of some presence (an element of trauma) induced in the subject that has experienced an encounter with the Real in the form of a more primordial motivation than the trauma, but which is itself induced by the experience of that trauma. This motivation, different 
from the trauma (which induces the subject to avoid the immediacy of The Real), fascinates the subject as a sheer possibility of trauma (first effects of the taking place of an encounter). This motivation/fascination correlates with The Real through establishing the fidelity in terms with it (the Real) which then makes the immediacy of the Real (traumatic experience) possible. The traumatic experience conditions the motivation/fascination in as much as it conditions its own taking place. Without this fidelity, a primordial fidelity, the "some-one" might attempt to avert the continuation of the taking place of the traumatic experience, which is needed in order for the subject to be born out of the very necessity to incessantly strive to avoid it. Such is this primordiality of the motivation/fascination, which is always already inscribed in the subject as a condition for his becoming. A fidelity par excellence which, by the virtue of the experienced, gives birth to the subject who is "called into action" by the very (traumatic) experienced. The call into action is a "call to think" in terms with the Real.

The always occurring fidelity/“call to action"/Continuer! (Lacan) of the lived is a fidelity to think according to the event (Badiou) or in terms with The Real (Laruelle). The subject who was created by the passing through him of the undergoing, the subject that is born out of the very necessity to incessantly strive to avoid it, is always a subject (without the Badiouian uncertainty whether the "someone" will answer the call). This subject in Laruellian terms is based on the Lived as its prelinugual real from which it is alienating through the instance of the Stranger (constituted by the trauma of estrangement). In Badiou, subjectivity originates in the event as that interruption of consistency through which the void's inconsistency is summoned to the surface of a situation, but the problem here is that the interruption in consistency is decisional.

To phrase this in Badiou's own language, the truth's procedure that is initiated by pure chance/accident in multiple situations is indifferent to the "subjective" decision of the subject to enact his fidelity or not to do so in regard to thinking the situation according to the event. Fidelity understood in the sense of relentlessness alienation from the inalienable immanence is the kind of fidelity that always produces a subject. This contention, that the subject resulting from an event/lived is a subject of truth, has nothing in common with what Hallward calls a moralizing presumption that "every human animal is a subject." (Hallward 2003, 143) It is so simply because we employ the term subject here (and now) only to denote the stage at which the truth procedure/trauma real-izes this subject (through the process of subjectivation) and who as such isdevoid of any worldly/discursive/social connotation. This is exactly what Hallward says further about Badiou, Lacan and Žižek, that to them subjectivation is essentially indifferent to the business and requirements of life as such. (ibid., 143) The claim that I make is that it is also indifferent to any ethical possibility at this moment. This is so because thought in terms of The Real/ in accordance with the event is not a recognizable truth, although it is transmitted to the subject from the event in the lived which is coded. Kolozova defines this thought as "absolute" in a very distinct sense: it is solitary in its singularity, an effort of Thought exposed in its ultimate incapacity to grasp and control the Rule-of-the-Real, yet attempting to correlate but together with it, without the support of a doctrinal web made of philosophical decisions. (Kolozova 2006, 41) 
The thought in terms of the Real/according to the event, always takes place in a particular situation to which the void of the event has belonged, and thus the truth to be produced is a truth for that situation. We can term "the site of primary resistance" the instance of thought correlating with the Real, the one that Laruelle calls a posture of thought. I call this process a primary resistance, exactly because it is here that the thought liberates itself from the obsession of genuinely being a (philosophical) thought, it is just a posture and it is a thought only because it correlates to the Real. Without this correlation, a pure posture fails to be any thought that can force the mediation of what is remembered into the discursive, and thus it is not a thought. Therefore, a posture is not a characteristic of the thought, it is what remains of thought which is exposed to The Real in its attempt to grasp it, but which fails to do so in the last instance. It is exactly this failure that leaves the thought in terms of The Real emptied and thus it appears, as Kolozova says, as a purposely produced crack within the always already contextualised thought. (ibid., 71)

To preserve this posture - keeping the opening alive -means keeping the "link" of the "primary resistance" alive while engaging in "the last resistance," the one of the effectuation/mediation of the truth in the discursive world (of the Language).

The "site of the final resistance," being the discourse/ language, is all that we have at our disposal as subjects (thinking in terms/accordance with the event/Real) to effectuate the fidelity that is to us a truth which is already actualized as a new (discursive/linguistic) situation. Thus the "final resistance" amounts to this actualization of the truth as a new situation, the becoming of the truth through language. Both Badiou and Laruelle engage in the operation of handling the "last resistance" before a truth actualizes as a new situation, an engagement that follows the same line, although I believe that Badiou has a higher (disinterested) interest to preserve that which itself opposes perseverance, being in correlation with the Real.

In understanding Laruelle's handling of the actualization of the truth in a new situation it is valuable here to quote Kolozova:

The Real imposes its own syntax - it cannot and does not establish perfect correspondence with a doctrine (a "philosophy"), it cannot be reflected by or reflect an entire theoretical universe. The Real, inasmuch as it is "the Lived," produces a "syntax" consisted of the symptomatology it displays in its uniqueness; the "behavior" of the Real can be "cloned," says Laruelle, into and from a concept. The Concept (the "Transcendental") and the Real belong to two entirely different orders, the first to that of Transcendence and the latter to that of Immanence. The two can never be reduced to one another - the Transcendental can attempt to "describe" (to "clone") the Real by virtue of acknowledging that it can never have the "same structure" (Laruelle 1989, 50, Kolozova 2009, 7).

When Badiou, on the other hand, brings in what he calls "subject-language," the language in which the truth is denominated, he immediately points to the fact that this language does not have a referent in the situation (knowledge/the discursive; Badiou 2005, 398) which means that it voids the phrases of this language of any referential (primitive) content. 
The subject-language involves the logic of difference which is visible only from within. (Žižek 2001) This language does not attempt to describe another meaning (hidden in the kernel of the real), it essentially empties the language of what it refers to in the situation, which Badiou calls primitive givens of knowledge. The reference will be given to the statements only when the situation will accommodate the truth by which it has been supplemented. Its emptiness refers to the fullness to come in the Lacanian manner: "A subject always declares meaning in the future anterior."

Elaborating the method of nomination (naming), Badiou points out that the crucial matter is what a name refers to which is precisely an indiscernible part of the situation. The nomination by the subject (language) is always under condition constrained to refer solely to what the situation presents. The names do not refer to anything in the situation, but they do designate terms "will have been" presented in a new situation that comes about through the very operation of the subject and his fidelity. (Badiou 2005, 400-406)

We find in Badiou this naming which is something that is similar to Laruelle's cloning. Laruelle clones The Real into and from a concept, while they both belong to two different orders and Badiou names the truth "to be," which verifies the name by virtue of its becoming. The language present in the discursive world/situation involves the Real through concepts, through attempting to describe it, and in Badiou it involves the truth through a creative process of naming. What is essential is that the discursive language that we know does not change under the effect of the Real/event, but it rather says the truth through the same (old) names which refer to something in the new situation, that something which is the truth that was accommodated in the situation through those names. It is thus the resistance which exists in this process of cloning and naming, the resistance of concepts becoming radical concepts and the resistance of names becoming truths that fights the primitive in the self-legitimizing nature of the discourse. The concepts and names perform this resistance through what Badiou calls "Forcing" and what Laruelle calls "thought of force." Forcing is the making of a statement (which uses naming) that can only be verified in a future situation, one which the forcing itself helps bring about, while it is the truth (referenced by a name by the subject in the new situation) that forces the situation to accommodate it. The statement, says Badoiu, can be forced by certain terms and not by others and this depends on the chance of the enquiries (ibid., 404). This presupposes that there is a generic truth in existence (outside the world), but which nonetheless can be believed by the subject who, through his fidelity to call into action by the event, moves on to discover what he has invented through the process of experiencing the encounter with the real and resisting (creatively naming) in the last site, that of language. Laruelle's "thought (of) force" comes from its determination in the last instance, which uses radical concepts that correlate with the Real (as naming correlates with the event), which are necessary to achieve this "thought of force."

The subject in the linguistic (final) site (of resistance) is the very operator of truth inasmuch as he produces it, without knowing it in the new situation. Heunder takes these operations without knowing the truth, because the statements of the subject-language he has made for the event can, by 
chance of enquiry through Forcing, force the situation to accommodate the truth. Similarly, the "thought (of) force," which I call the "final site of resistance," cannot be such without cloning the real using radical concepts.

An ethical question arises here. It seems that in order for the language to mediate the truth, through naming or radical concepts, it must operate through a kind of requirement that the concepts must be radical and names should not mean anything for the discursive/language of the situation. To clarify the possible confusions, that might arise from embarking on a search for unique privileged concepts and names (as qualified bearers of truth to be mediated), the best way is to go from the supplemented situation by the event/encounter in which the truth is always already mediated (through concepts and naming) to the nature of the encounter/real, to what happens when the real/event disposes its effects on the subject. Thus, there must be some new meaning present in the language that addresses/ describes the supplemented of the situation in relation/accordance with that which has supplemented it (the Real/ Event). Only then can we speak of a procedure of truth to have taken place. So it seems that the actualization of the event (truth) is bound by some change (novelty in Badiou) which effectuates itself only after that event has taken place as a result of that effectuation.

What has happened, then, if there is no change in the discourse/language/situation after the resistance which happens as the result of the fidelity to the event/the Real? If there is no way to decide (Badiou) upon the fidelity and if there is always a potential subject produced by the event/encounter/trauma which, via the traumatic/ fascination, induces his fidelity/"call into action" to link (primary resistance) what has happened to him with what he knows, then we must look at what takes place in the final resistance. The instance of the mediation of the truth (always already mediated, but not in the last instance) via the language/the discursive. I propose to name this second site of resistance of the truth the site of the ethics (of truth). Cloning the real through radical concepts and naming the unnameable which might later become a truth is, radically, a provocation, not a prescribed procedure (with characterisations of proper concepts and names for the purposes of truth). The concepts are termed as radical only because they distinguish from the ones (which always retain the potential [Badiou] of radicality in another supplemented situation) the "thought (of) force" cannot use in order to fulfil its induced unilateral fidelity (of primary resistance) to the sheer taking place of the Real. Thus these concepts are not radical in the sense that they differ from other concepts present in the discourse, their radicality stems from the fact that they succeed in correlating with the real, in and for a given situation, to which the event of the void belonged.

Similarly, the names of Badiou's subject-language are not particular names that have the affinity to be emptied of (a primitive) reference according to the knowledge of the situation in the midst of an event of that situation. This language is used to denominate the truth as an enquiry in order to state what an event has inaugurated/promised, the truth which is not yet mediated (it is still indiscernible), but denominated. The names are not predetermined in their ability to name the truth in the supplemented situation, but, to the contrary, if the fact that their enquiry succeeds in referring to something different (the 
indiscernible, by accommodating it as a truth in the situation), then what they referred to in the situation (when the truth was indiscernible) makes them names for the purpose of truth, which has been produced through the event of the void of that particular situation. The subject thus becomes a subject only by the chance of that enquiry.

Thus, the subject being unaware of the truth that is brought through him into a situation is not aware of which names to use in denominating the event, up until when these terms/names refer to the truth, thus producing him as a subject of truth. Badiou says that we must abandon any definition of the subject which supposes that he knows the truth or that he is adjusted to the truth.

If the names used by this provoked subject fail to refer to the truth, the subject fails to become a subject (of truth) and thus the whole procedure of truth has failed. Similar to that, if the concepts fail to correlate with the real (they are not/do not become radical), then they will not clone the real, and so the encounter will not mediate any sheer experience with the real into the world. It seems here that, since the subject is unsure which names will term the truth, or which concepts, after being able to correlate with the Real, will clone the Real, all options for an ethics of truth are lost. This attempt to sketch an ethics of truth simply leads to pure coincidence, or Discursivity of Coincidence (for the purpose of truth), and therefore ethics is rendered impossible.

To address this crucial issue of ethical possibility of the discourse, I propose to focus on the procedures that
Badiou and Laruelle explore. While Badiou mentions a practising of a creative process of naming, Laruelle insists on a correlation with the real of the concepts. Although Badiou's subject cannot verify whether a term that forces a statement belongs to the indiscernible or not, he does undertake a certain procedure. And from Laruelle we see the insistence on fidelity, the actuality of fidelity to the fidelity, induced by the encounter with the real, in correlating with the real of the concepts that belongs to the order of the transcendence, not the real. Thus, both Badiou and Laruelle speak of something that is of the type of the encounter/event but is not made of the same material as the ones that occur in the encounter with the Real/Void. A kind of fidelity is present, a fidelity to this creative practise, a fidelity to the correlation which becomes an imperative at the level of the transcendence (radical concepts, names that are emptied) which attempts to "describe the real" by virtue of acknowledging that it can never have the "same structure." That one-ofa-kind-description is the one that Laruelle undertakes in using radical concepts and the one that Badiou does with the subject-language. This description is the truth-promised, not yet mediated in the discourse/language, which provokes the subject. The transference of this unmediated truth-as-a-promise into the language/discourse requires a fidelity to that which is (now) known (but is not yet referred to with a name in the language)as opposed to what is still unknown during the sheer taking place of the Real/ event. This is a fidelity that is not of the order of the encounter, but is a radical provocation. It is a provocation that does not fall into the Badiouian trap of maintaining an uncertainty of fidelity, which enables a decision for ethics. An ethical decision to fidelity that is needed for the transference of the promised truth in the language/ discourse would revert the whole process back to the 
point of philosophical decision and thus dismantling the whole process of the ethics of truth, a truth which resides outside of the philosophical/discursive thought, but which is always already mediated into philosophy/ discourse. This provocation (a-kind-of-fidelity) could be described as a provocation to "try the correlativity," "try the denominating," it is a provocation and not a choice precisely because the subject does not (and cannot) know whether the concepts he uses will correlate with the Real or the names that force the situation will belong to the indiscernible - the truth. It is a provocation and not a fidelity (to encounter/event), of the order of the encounter, simply because in the transference/exchange between the transcendence and the discursive/linguistic there is no encounter/event that will induce fidelity.

An ethical discourse still remains a discourse, it does not operate with anything else other than thought and language. An ethical discourse is the one that does not search for truths through Foucauldian regularities, through which the postmodern discourses arrive at their own truths (within what is already known), because it implies that this kind of operational referencing of thought and language involves from its very beginning a decision which is a decision to refuse what is outside of the World, that is, to refuse the Real out of their operations. As such, those kinds of discourses limit the operational possibilities of thought and language to only those possibilities which fall within this established limit (prescription) of regularity, that use primitive givens of knowledge - resulting in dogmatic discourses (from the perspective of chance beyond knowledge of the situation). It is not only the philosophical decisionism that is the main problem at stake here, a problem of employing decisions as a method of seeking truths, but it is also the concrete decision to refuse the real. We know from Lacan, Badiou and Laruelle that the subject's experience cannot be limited only to what he knows, but he is rather exposed to the possibility of surprisingly being "hit by the Real" or to suddenly finding himself in the midst of an event. It is this experience, which as Lacan says, will determine all that follows that implies a heretical approach to ethics abandoning the established knowledge (of the situation). This experience with the real/event is, as described earlier, an experience that is completely new, non-reflected and non-decisional for the subject, and as such it cannot follow the discursive prescribed regularities. A part of philosophy and psycho-analysis has indeed been dealing with the Real but it has never accepted to think in correlation to the real. Laruelle's criticism for these thinkers (of philosophy and psychoanalysis) shows the radical approach of non-philosophy to the Real and thus the difference from philosophy, which is why I believe this quite lengthy quote of his is worth sharing here:

In other words, Lacan and Derrida are moved by antithetical motives with regard to the real: the former wants to exclude all relation, while the latter is content to differentiate relation through its other and hopes to find the real in an affect of absolute Judaic alterity. Their difference can be situated between two conceptions of the other, but it does not basically touch on the real. Both cases remain within the realm of philosophy and seek immanence, the without-relation, through opposition or in terms of an ultimate reference to transcendence. Under these conditions, the real cannot be radically relationless, even in Lacan where the real and the symbolic are linked through topology...This is the place of the non-philosophical concept of uni-laterality: between Hegel who reduces it to an abstraction of the understanding; Lacan who ultimately does not understand it and tolerates it only in order to cancel it in the 
signifying chain through which he thinks he acknowledges it; and Derrida and others, who try to give it a status but still within the realm of philosophical exteriority. (Laruelle 2004)

The ethical problems that Laruelle notes in philosophy's approach to the Real, as I claim as well here cannot as such amount to an ethical discourse, precisely because to its (philosophy's) thought and language the Real is an exteriority. Ethics of a discourse is inescapably linked to operations of language and thought, but to a thought that thinks in terms of the Real (Laruelle) or according to the event (Badiou), and a language that does not put limits to radical concepts to become such within its always already discursive nature and which does not exclude the chance for certain names that force a statement to belong to a truth only because in the situation before the event they referred to something else.

Bearing Laruelle's criticism in mind, we can say that the essence of ethics (of truth) relies on our theoretical approach to the Real. And the "theoretical" will always (already) remain discursive. A proposal for an ethical discourse is not an anti-discursive proposal, since thought and language are the only two operatives at our human disposal to mediate the lived/experienced (non-reflected) in the world (which is reflected). It would be seemingly disastrous to destroy Discursivity as an attempt to push the reality/world into the realm of the Real, which is an impossible and absurd attempt. The discourse that can be ethical is the discourse that does not seek to remove or replace the reality/world/positive, even though it brings radical change through the truths that it produces. The operations of an ethical doctrine only give positivistic tendency to the always already positive (World), which is one of failure to gasp the unknown/void/the Real in the last instance. What is possible is only the failure to grasp the void (in the last instance); thus the world is always already a positive. An ethical doctrine stands for more positivity in the positive/world/discourse which is achieved through the failure (in the last instance) of a successful event. It can never grasp (in the last instance) the Real/void, therefore it will never cease to be positive itself. It is thus heretical in relation to the conservation of a finite positivity of the discursive/world.

I called primary resistance all that happens to the truth in the midst of an event/encounter, and I called final resistance all that which happens in the transmission of that truth in the language/discourse. Since for the primary resistance the subject receives via the trauma an induced fidelity, without any choice over a possible decision which always determines all that follows, the possibility of a truth is always unilaterally generated and therefore we always have a possibility of subject of truth who cannot decide whether to experience or not an encounter/ event. This is why there cannot be talk of any ethics in this site of resistance. The primary site of resistance is the site of truth, of the primary truth, the first product of a truth procedure.

I call the final resistance, the provocation that this truth has brought upon the subject, the provocation of its transmission into the language/discourse. And it is, again, not a matter of decision to take the challenge or not, simply because the subject does not know anything that informs his choice. All he knows is the provocation, put 
in Badiouian terms, to link what he has experienced with what he knows. And what he knows is the language/the discursive, so he will use this site for the chance of a final result of a truth procedure, the always already discursive truth. The chance of success or failure for this provocation lies beyond the subjects' decisions. For we cannot know if the names that the subject uses as his subject-language in the midst of an event will belong to the truth or if they will belong to the situation to which they belonged before the event. In the latter case, the subject will fail to become a subject of truth and thus we have an indication that the truth procedure has failed. In both cases the language will remain the same, the only thing that will change is what it accommodates. Destroying the language is the disastrous destruction of the discourse mentioned earlier. So it is exactly in the language that we already know where the radical concepts of Laruelle and the names of the truth of Badiou are located. It is in the concepts used by Marx where Laruelle is looking for those radical concepts and his success (which does not depend on him) can in the future amount to Badiou's Haydn event.

It is this site of resistance (of language/discourse) that, if it accommodates the statement forced by a term that will belong to the truth, produces the subject as a subject of truth and this is why I name it the "site of final resistance" of the truth. If the primary site of resistance was the one of the truth, the second one is of ethics. I claim that an ethical discourse is a discourse in which its two main operatives, thought and language operate through two sites of resistance, the first being that of truth, and the second that of ethics, an ethics of a provocation. A provocation to our knowledge. Badiou says something similar for the truth. "Truth is always a challenge, a challenge to what we already know." But then he moves on to say that it is openness and commitment. And here I take my distance from him, because, as I have explained earlier, the subject cannot decide to "close" himself to the encounters with the Real. They happen to him unpredictably and unwillingly (the subject is borne out of the very necessity to incessantly strive to avoid the traumatic experience [Kolozova]). And, further, the subject cannot enact his commitment, since, as Lacan says, the encounter (for which the subject also cannot decide whether it happens to him or not) will determine all that follows. And this "all that follows" might fail to produce the truth but it will produce a provocation, of the result of which the truth will appear or will fail to appear in the language/ discourse. Therefore, although truth, through the truth procedure, will bring about a provocation, provocation is not truth itself, it is the way to truth, and thus - it is ethics.

\section{References:}

Badiou, Alain. 2001. Ethics: An essay on the understanding of evil, trans. Peter Hallward. London: Verso.

2005. Being and event, trans. Oliver Feltham. New York: Continuum.

Hallward, Peter. 2003. Badiou: A subject to truth. Minneapolis and London: University of Minnesota Press.

Kolozova, Katerina. 2006. The Real and "I:" On the limit and the Self. Skopje: Euro-Balkan Press.

2009. Thinking the political by way of 'radical concepts.' International Journal of Žižek Studies 3,1. http://www. zizekstudies.org/index.php/ijzs/article/view/159/268 (accessed October 1, 2011). 
Laruelle, François. 2004. A new presentation of non-philosophy. Organisation Non-Philosophique Internationale. http://www. onphi.net/texte-a-new-presentation-of-non-philosophy-32. html (accessed October 1, 2011).

Lacan, Jacques. 1998. The four fundamental concepts of psychoanalysis. The seminar of Jacques Lacan, Book XI, ed. Jacques-Alain Miller. trans. Alan Sheridan. New York and London: W. W. Norton \& Co.

Žižek, Slavoj. 2001. Welcome to the dessert of the Real. Reflections on WTC: Third version. July 10 2001. European Graduate School. http://www.egs.edu/faculty/slavoj-Žižek/articles/welcome-to-the-desert-of-the-Real (accessed October 1, 2011) 